\title{
Enterovirus Associated Placental Morphology: A Light, Virological, Electron Microscopic and Immunohistologic Study
}

\author{
APARECIDA GOMES PINTO \\ GARCIA $^{b}$, NADIA GOMES DA SILVA \\ BASSO $^{a}$, MARIA EVANGELINA \\ FERREIRA FONSECA ${ }^{a}$, JOSE \\ AUGUSTO TEIXEIRA ZUARDI \& \\ HELOISA NOVAES OUTANNI
}

\begin{abstract}
Departamento de Anatomia Patologica do Instituto Fernandes Figueira-FIOCRUZ - Rio de faneiro-Brasil

${ }^{a}$ Departamento de Virologia e Setor de Microscopia Electronica do Instituto de Microbiologia da Universidade Federal do Rio de Janeiro-Brasil. (Part of M.Si. Thesis of Basso, NGS under supervision of Fonseca MEF, with grant awarded by FINEP, CNPq and CEPEG, Brasil).

${ }^{b}$ To whom corresepndence should be addressed, at: Instituto Fernandes Figueira-Avenida Ruy Barbosa 716-Rio de JaneiroCEP 22.250-Brasil
\end{abstract}

Paper accepted 30.4.1991

\begin{abstract}
SUMMARY
The purpose of this study mas to identify the possible effect of enteroviruses on placental tissue. Seventy-eight pregnant women were studied throughout their pregnancy: enteroviral infection was detected by faecal viral isolation and seric neutralization of previously identified virus in cell culture. In 19 cases of confirmed maternal infection, placentae were examined grossly, by optical microscopy, immunohistochemical and electron microscopic methods. Ten term placentae from women included in the study, with no clinical, serological or virological evidence of enteroviral infection, mere used as control, and examined by gross and optical microscopy. In 17 specimens (echoviruscoxsackievirus) an haematogenous placentitis was suspected on the basis of gross observation. Microscopic lesions mere similar to those found in other viral infections, with specific features. The nature of the inflammatory reaction pointed to the presence of an acute type of haematogenous placentitis, not present in placentae of the control group.

The authors $(A A)$ comment on the results and present the hypotheses about the available data: (1) maternal enteroviremia and faecal virus shedding without placental invasion, placentary damage being an unspecific consequence of infection; (2) direct virus-induced injury is not the only possible cause for the lesions: (3) placental
\end{abstract}


enteroviral infection occurred mith placental pathology but the virus did not cross the organ as the nemborn had no signs of infection.

\section{INTRODUCTION}

Although unusual, transplacental transmission has been shown to occur with echovirus, coxsackievirus and poliovirus (Cherry, Soriano and John, 1968; Jones et al, 1980; Modlin, 1986; Toce and Keenan, 1988; Basso et al, 1990; Garcia et al, 1990). In the 1950s these viruses were occasionally isolated from placentae, but under histological examination, morphological placental abnormalities were never identified (Baskin, Soule and Mills, 1950; Kibrick and Benirschke, 1958). Attempts to demonstrate the transplacental passage of viruses Coxsackie B3 and Echo 11 by in vitro perfusion were unsuccessful (Amstey et al, 1988); this suggested that transplacental passage of these viruses does not occur readily and that most neonates of infected mothers could be unharmed.

As all enteroviruses are similar physically, chemically and genetically, it seems reasonable to consider them together. In order to detect the occurrence and prevalence of enterovirus infection in pregnant women and the possible harm to the fetuses, a prospective study was conducted in patients from the antenatal care service of Instituto Fernandes Figueira, FIOCRUZ, Rio de Janeiro, Brazil. The women were monitored from the beginning to the end of pregnancy; several maternal specimens were collected for virological and serological studies, as well as the respective placentae, in cases of confirmed maternal infection. Here, we report on a gross and histopathological study of 19 placentae from which enteroviruses have been isolated. The morphological study was accompanied by immunohistochemical and electron microscopic methods and was correlated with serological findings.

\section{MATERIALS AND METHODS}

Seventy-eight pregnant women were randomly selected and monitored for enteroviral infection until delivery. Blood samples were collected at the beginning and end of pregnancy; faecal specimens were collected monthly. Immediately following labour placentae were sent to the laboratory for pathological study and tissue samples were obtained for viral, immunohistochemical and electron microscopic studies. Several types of echovirus and coxsackievirus were isolated from 19 placental specimens. Ten term placentae from women included in the study group, with no clinical, serological or virological evidence of enteroviral infection, were used as control.

\section{Virology}

Faecal and placental extracts were obtained and injected into cell cultures (LLC-MK2, VERO and HEP2 lineages). The isolated viruses were titled and identified by neutralization test in cell culture LLC-MK2, using Melnick's sera (Melnick, Wenner \& Philips, 1979). The neutralization test in the LLC-MK2 lineage was also done in each case, with the paired maternal sera, against the isolated virus. Immunofluorescence and immunoperoxidase assays were applied in deparaffinized placental specimens:

Immunofluorescence assay. Antisera against different echoviruses were obtained by i.v. injection in rabbits. After separation through Sephadex G25 column, the IgG fraction was used in 
the assay followed by addition of goat serum against rabbit $\operatorname{IgG}$, and labelled with fluoresceine (Sigma), (Nahmias, Shore and Del Buono, 1974).

Immunoperoxidase assay. Rabbit antisera against echoviruses were obtained by i.v. injection. After separation of immunoglobulins, through Sephadex G25 column, the IgG fraction was used in the assay, followed by addition of goat serum against rabbit $\operatorname{IgG}$, and labelled with peroxidase enzyme (Sigma), (Morisset, Kurstak and Kurstak, 1974).

\section{Macroscopic and light microscopic examination}

After delivery, the placentae were sent to the laboratory, where they were examined according to the method describcd by Bernirschke and Driscoll (1967). The placentae werc weighed after the membranes, umbilical cord and adherent clots had been removed. The specimens were immersed in a large volume of 10 per cent formalin. For microscopic examination, sections from near the centre (including chorionic and basal plates), margin and gross abnormality sites were taken: a roll of membranes, and both cross and longitudinal sections of the umbilical cord were always examined. Formalin-fixed blocks were embedded in paraffin and sections were routinely stained with haematoxylin-eosin. Selected tissues were stained with phosphotungstic acid-haematoxylin, periodic acid Schiff (PAS), Weigert's method for elastic fibers, Gomori's one-step trichrome and Gomori's method for reticulum.

\section{Electron microscopy}

Fresh placental samples were mixed with 2.5 per cent glutaraldehyde and 1 per cent tetroxide, dehydrated in graded ethanols and embedded in polylite resin. Ultrathin sections, stained with uranyl acetate and lead citrate, were observed with the electron microscope EM301, Philips.

\section{RESULTS}

The data of macroscopic examination of placentae, gestational age, fetal and placental weights are included in 'Table 1, as well as the viral types isolated from placentae and maternal faecal specimens. The clinical data on the neonates, obtained before discharge from nursery, and the maternal serolngy (five cases) are also added. In all but one case (number 4), the pregnancies were full term; there were five small-for-date infants (cases 3, 4, $5,7,15$ ). The placental weight was considered normal (Philippe's Scale, 1974) in 11 cases (numbers 1, 6, 8, 10, 11, 12,14, 16-19) and underweight in eight (numbers 2-5, 7, 9, 13, 15). Placental infection was suspected on the basis of gross examination in 17 cases and was characterized either by mild opalescence of the membranes associated (or not) with an abnormal appearance of Wharton's jelly and thickening of umbilical vessels (Figure 1). Meconium staining of the membranes of the chorionic plate and umbilical cord was commonly noted. No gross abnormalitics wcre detcctcd in two cases (numbers 3,4). Thrombi were a relatively frequent finding on the maternal surface of the placentae.

The clinical data on the newborn infants refer only to those obtained during the permanency in the nursery (3-51 days). In ten children (cases 1, 2, 5, 8, 11, 13, 14, 17, 18, 19) no clinical abnormalities were noted. In three cases (numbers $3,12,15$ ) phototherapy was used to control physiologic icterus: prolonged jaundice was observed once (case 4). In case 9 a cardiopathy was detected and in case 16 cataract was observed. 


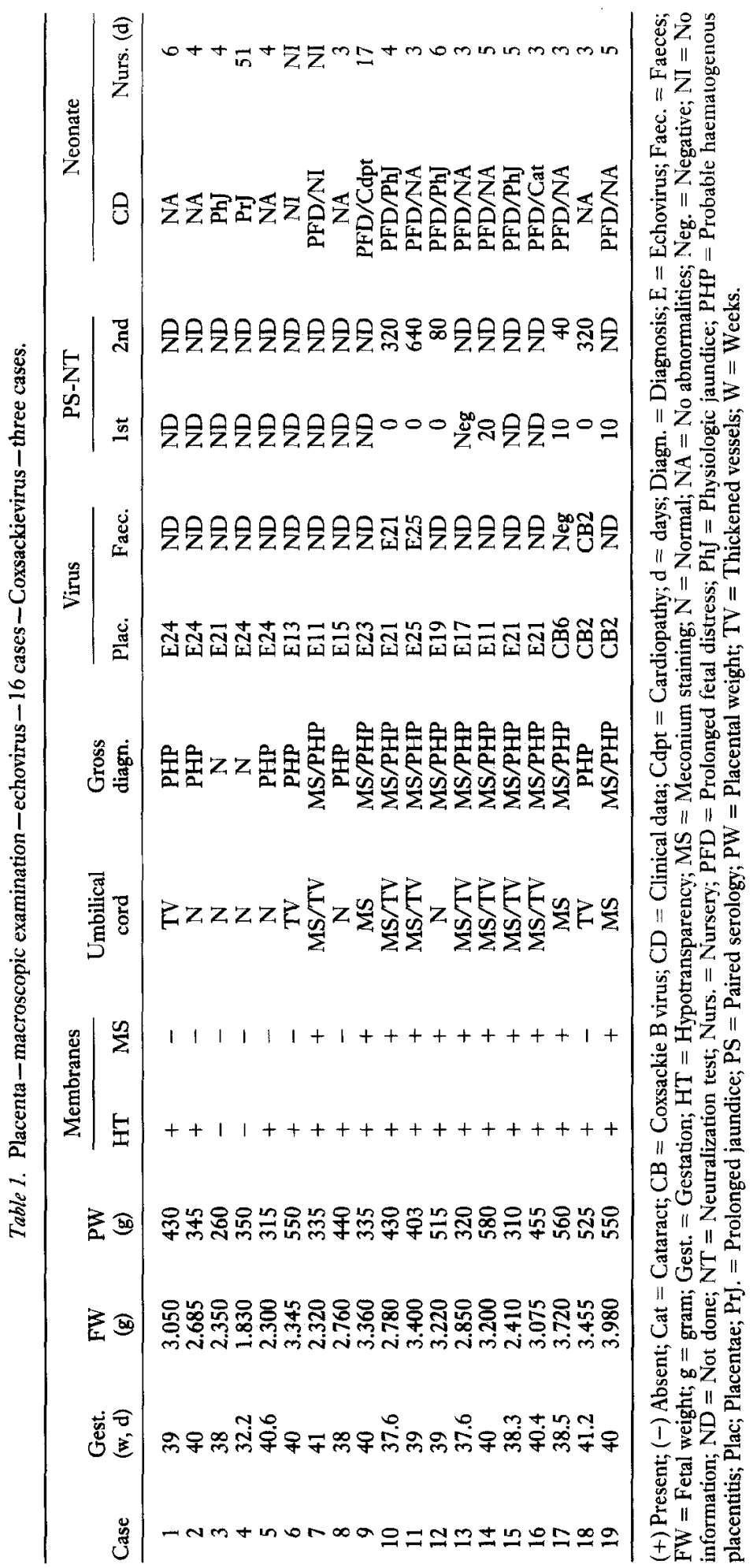




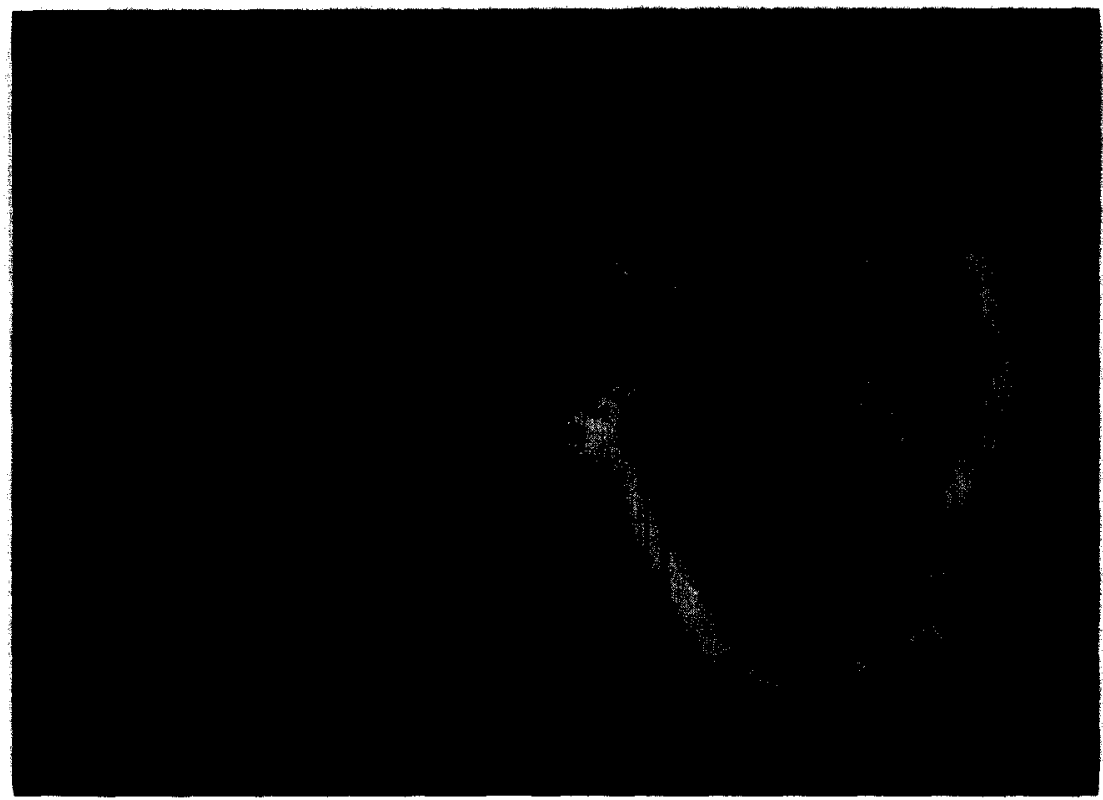

Figure 1. Placenta-Intermingled areas of opalescency and normal transparency can be seen in the chorionic plate.

The data of gross examination of the control group placentae gestational age, fetal and placental weights are presented in Table 2 . The clinical data on the newborn and period of nursery permanency are also included. In all cases, the pregnancies were at term, although in two (numbers 5,7 ) the exact age in weeks was not known. The weights of the newborn showed some variation from normal values. The placental weight was considered normal in four cases (numbers 2, 4, 7, 10) and less than normal in six (numbers $1,3,5,6,8,9$ ). In two cases $(2,10)$ a probable diagnosis of haematogenous placentitis was confirmed as well as an ascending type of placental infection being suspected in case 8; the neonates presented no

Table 2. Placenta-macroscopic examination-control group-ten cases.

\begin{tabular}{|c|c|c|c|c|c|c|c|c|c|c|c|}
\hline \multirow[b]{2}{*}{ Case } & \multirow{2}{*}{$\begin{array}{l}\text { Gest. } \\
(\mathrm{w}, \mathrm{d})\end{array}$} & \multirow{2}{*}{$\begin{array}{l}\text { FW } \\
(\mathrm{g})\end{array}$} & \multirow{2}{*}{$\begin{array}{l}\text { PW } \\
\text { (g) }\end{array}$} & \multicolumn{2}{|c|}{ Membrane } & \multirow{2}{*}{$\begin{array}{l}\text { Umbilical } \\
\text { cord }\end{array}$} & \multirow{2}{*}{$\begin{array}{l}\text { Gross } \\
\text { diagn. }\end{array}$} & \multicolumn{2}{|c|}{ Virus } & \multicolumn{2}{|c|}{ Neonate } \\
\hline & & & & HT & MS & & & Plac. & Faec. & $\mathrm{CD}$ & Nurs. (d) \\
\hline 1 & 37.1 & 2.430 & 292 & + & - & $\mathrm{N}$ & $\mathrm{N}$ & $\mathrm{Neg}$ & $\mathrm{Neg}$ & PhJ & 13 \\
\hline 2 & 40 & 3.370 & 435 & + & + & MS & PHP & $\mathrm{Neg}$ & $\mathrm{Neg}$ & $\mathrm{NA}$ & 4 \\
\hline 3 & 40.4 & 2.885 & 320 & + & - & $\mathrm{N}$ & $N$ & Neg & Neg & $\mathrm{NA}$ & 3 \\
\hline 4 & 39 & 3.325 & 500 & + & - & $\mathrm{N}$ & $\mathrm{N}$ & Neg & $\mathrm{Neg}$ & $\mathrm{NA}$ & 8 \\
\hline 5 & $\mathrm{~T}$ & 3.320 & 405 & + & - & $N$ & $\mathrm{~N}$ & Neg & $\mathrm{Neg}$ & NA & 8 \\
\hline 6 & 39.3 & 2.815 & 325 & - & - & $N$ & $\lambda$ & Neg & Neg & NA & 6 \\
\hline 7 & $T$ & 3.745 & 470 & + & - & $\mathrm{N}$ & $N$ & Neg & $\mathrm{Neg}$ & $\mathrm{NA}$ & 3 \\
\hline 8 & 40 & 3.160 & 380 & + & - & $N$ & PAP & $\mathrm{Neg}$ & Neg & NA & 7 \\
\hline 9 & 38.2 & 3.170 & 420 & + & + & $\mathrm{N}$ & MS & Neg & Neg & PFD/NA & 4 \\
\hline 10 & 38.2 & 3.195 & 505 & + & - & TV & PHP & $\mathrm{Neg}$ & $\mathrm{Neg}$ & $\mathrm{PhJ}$ & 7 \\
\hline
\end{tabular}

(+) Present; (-) Absent; CD = Clinical data; $\mathbf{d}=$ days; Diagn. = Diagnosis; Faec. = Faeces; FW = Fetal weight; $\mathrm{g}=$ gram; Gest. $=$ Gestation; $\mathrm{HT}=$ Hypotransparency; $\mathrm{MS}=$ Meconium staining; $\mathrm{N}=$ Normal; NA $=$ No $\mathrm{ab}-$ normalities; Neg. $=$ Negative; Nurs. $=$ Nursery; $P A P=$ Probable ascendant placentitis; $P F D=$ Prolonged fetal distress; PhJ = Physiologic jaundice; PHP = Probable haematogenous placentitis; Plac. $=$ Placentae; PW $=$ Pla cental weight; $T=$ Term; $T V=$ Thickened vessels; $w=$ Weeks. 


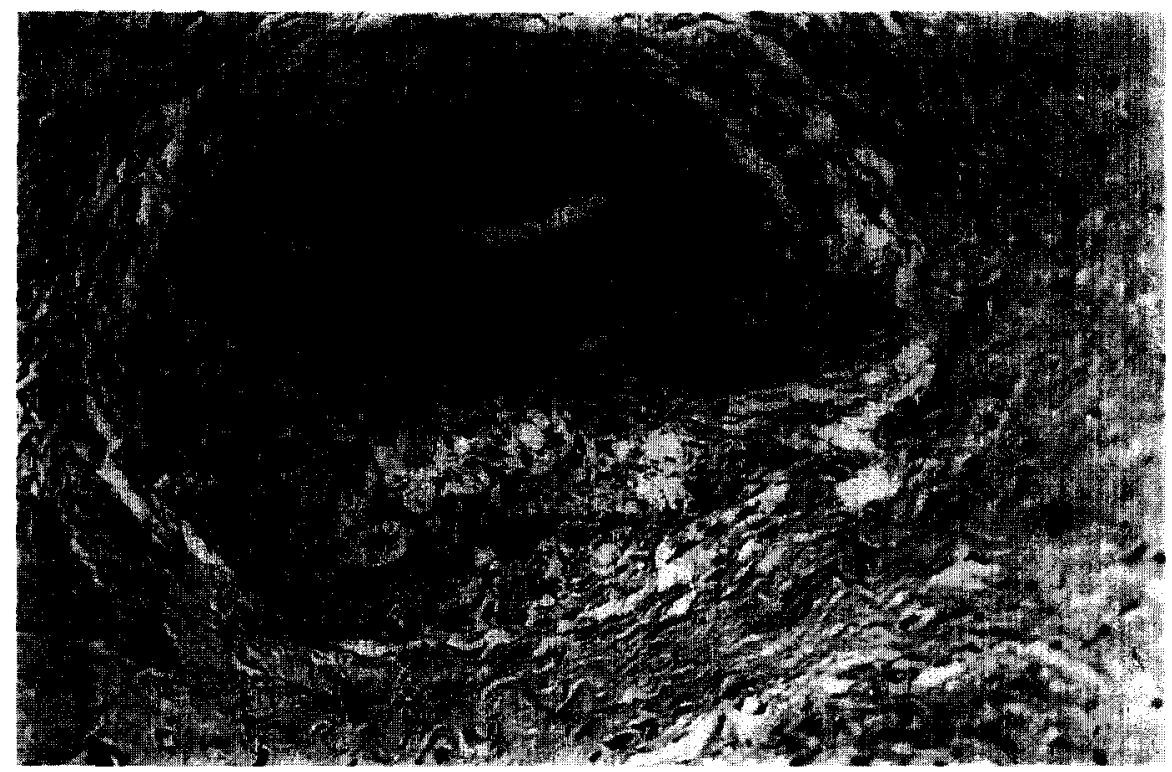

Figure 2. Chorionic vessel showing segmentar mural myolysis $(\mathrm{HE} \times 125)$.

abnormalities in eight cases (numbers $2,3,4,5,6,7,8,9)$; only in two cases $(1,10)$ was there a need for phototherapy to control physiologic icterus.

Placental microscopic examination. The main histological findings are shown in Table 3 . Membrane infection: only in four cases (numbers 9, 14, 16, 17) was a mild inflammatory infiltrate present in the chorium and amnion of the chorionic plate, this was mainly focal and was represented by mononuclear and neutrophil cells. In the chorium laeve the same aspect was observed in five cases (numbers $3,9,17,18,19$ ). Vasculitis, involving the entire vascular circuit, was present in all cases. Chorionic and umbilical vessels exhibited areas of mural myolysis, oedema, scanty perivascular mononuclear infiltrate (Figure 2) and marginalization and invasion of the walls by leucocytes. In the truncal vessels heavy mononuclear infiltrate was a common finding (Figure 3). In two cases (numbers 5,7 ) generalized haemorrhagic endovasculitis was detected. In several cases (numbers $1,3,4,5,7-12,14,15,17,18$ ) a particular aspect of placental parenchyma was observed.

The lesions ranged in size from individual villi to massive areas of necrosis (Figure 4), the intervillous space being occupied by severe leucostasis and fibrin strands over the villous structures, where bacteria were not seen. These areas were irregularly disseminated in the villous plate more commonly in the periphery of the lobules. Villous inflammation comprised necrosis of trophoblast, infiltration of the stroma with inflammatory cells and activation of the endothelium of local vessels. Besides these areas of acute reaction, proliferative-necrotic and mild or severe reparative villitis was a prominent feature in eight placental specimens (cases 4 , $5,7,10,13,14,16,19)$ (Figure 5); the intravillous infiltrate consisted of histiocytes and lymphocytes involving the villous vessels. In the decidua basalis and capsularis, clusters of mononuclear inflammatory cells surrounding or lying adjacent to vessels were always detected. It was commonly observed that local thrombi invading the villous plate, often reached the subchorionic area (Figure 6). 


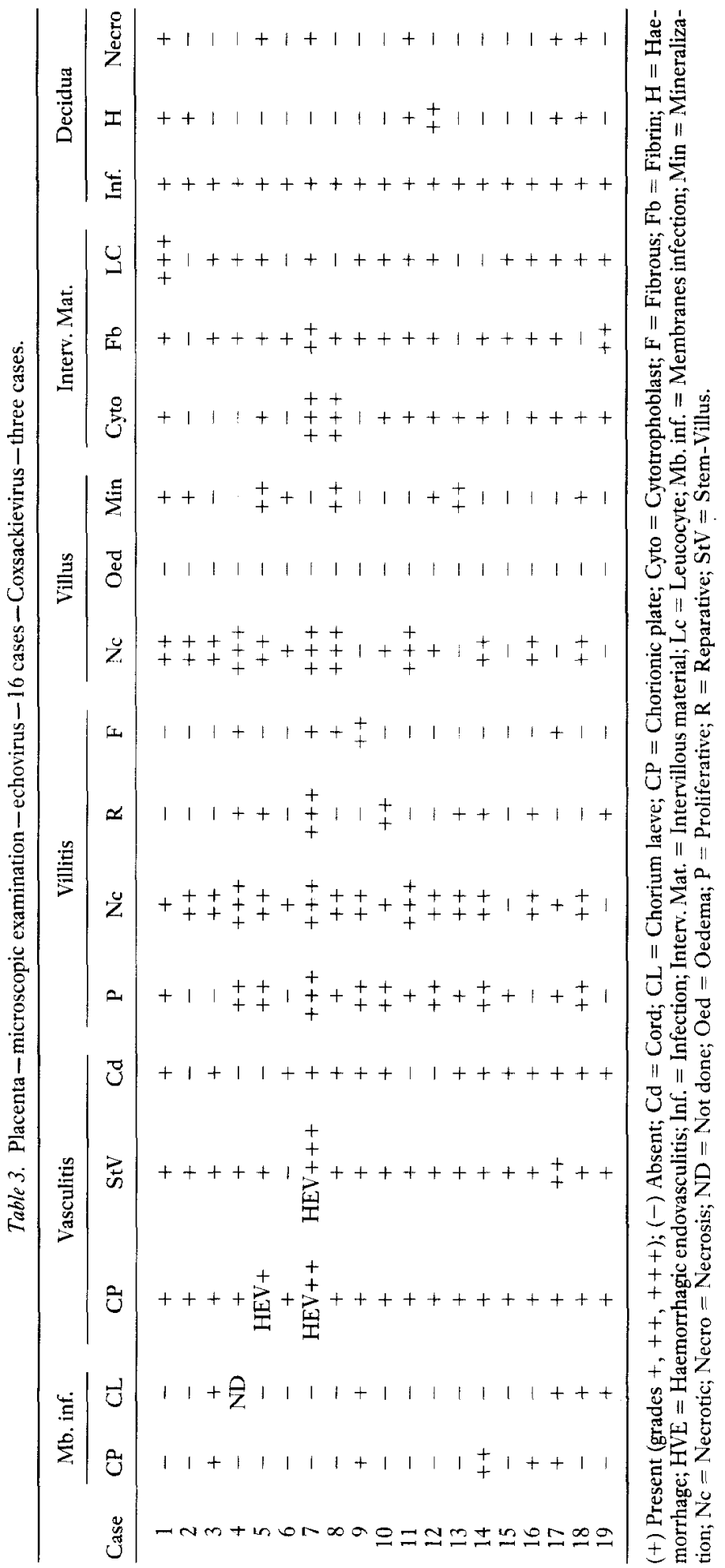




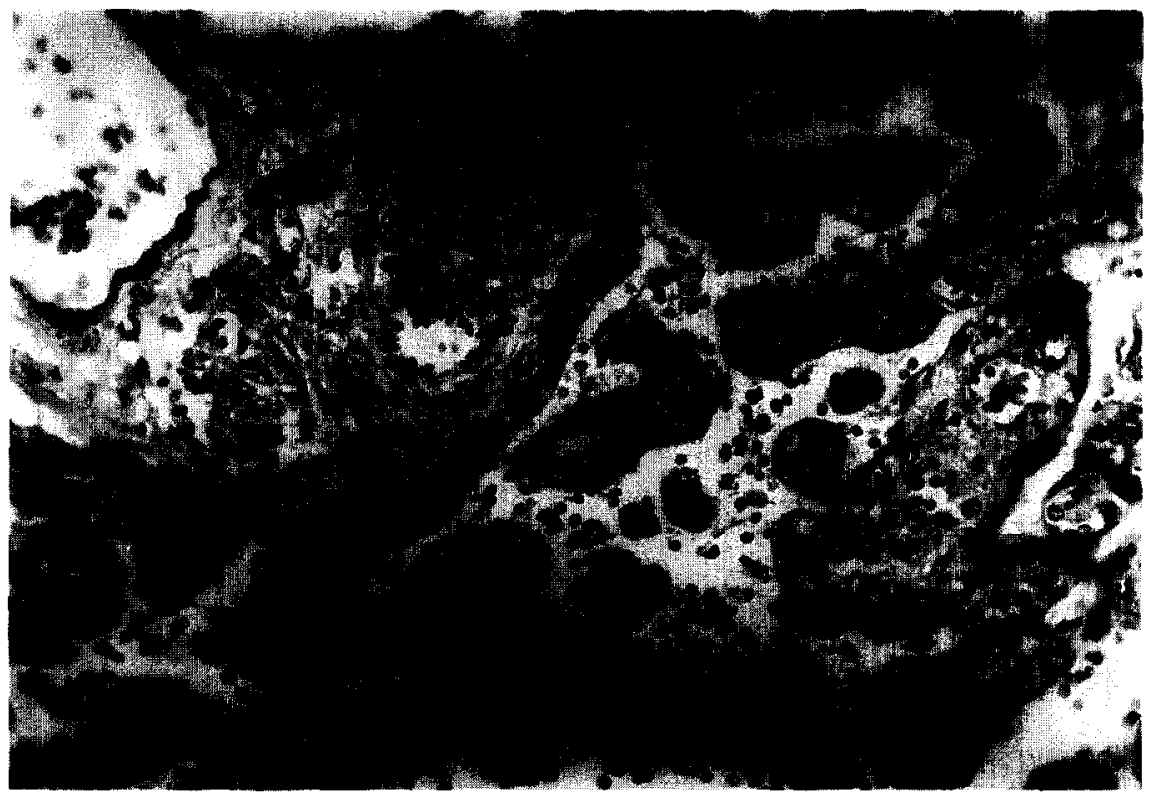

Figure 3. In a small stem villous perivascular mononuclear infiltrate is observed (HE $\times 125$ ).

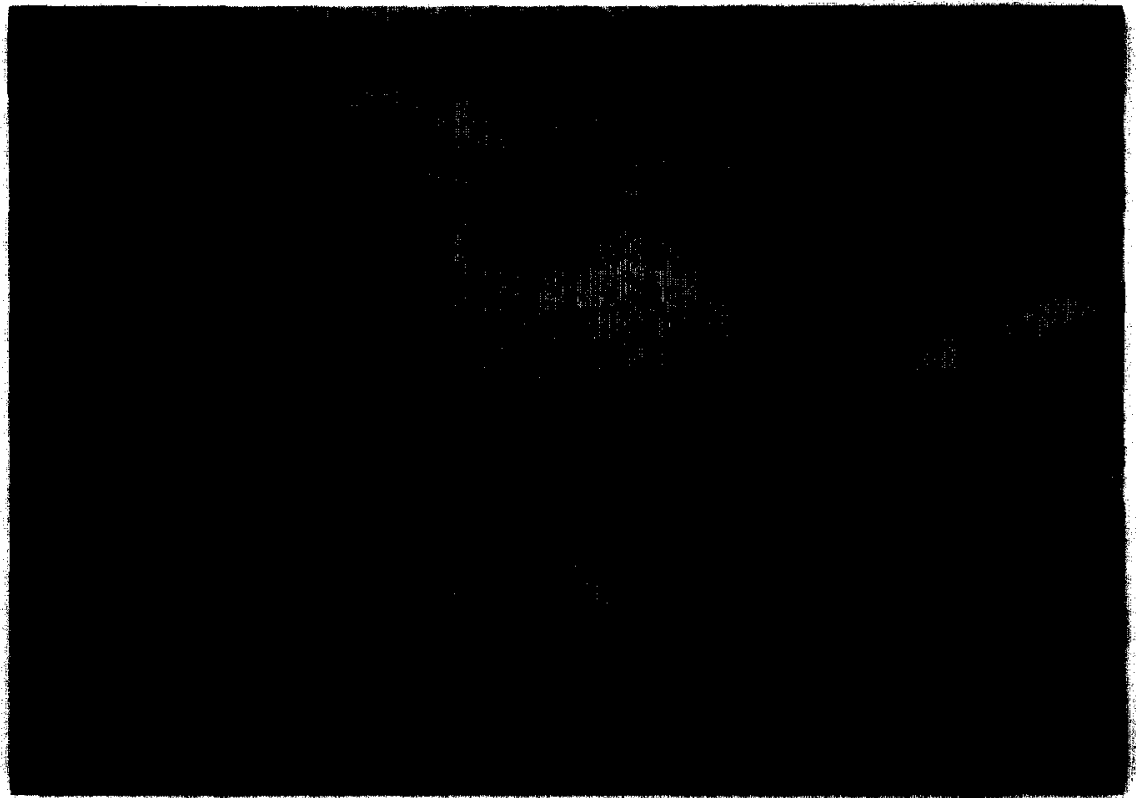

Figure 4. Intervillous thrombus with numerous maternal leucocytes inflammation and necrosis of villi (Giemsa $\times$ 44). 


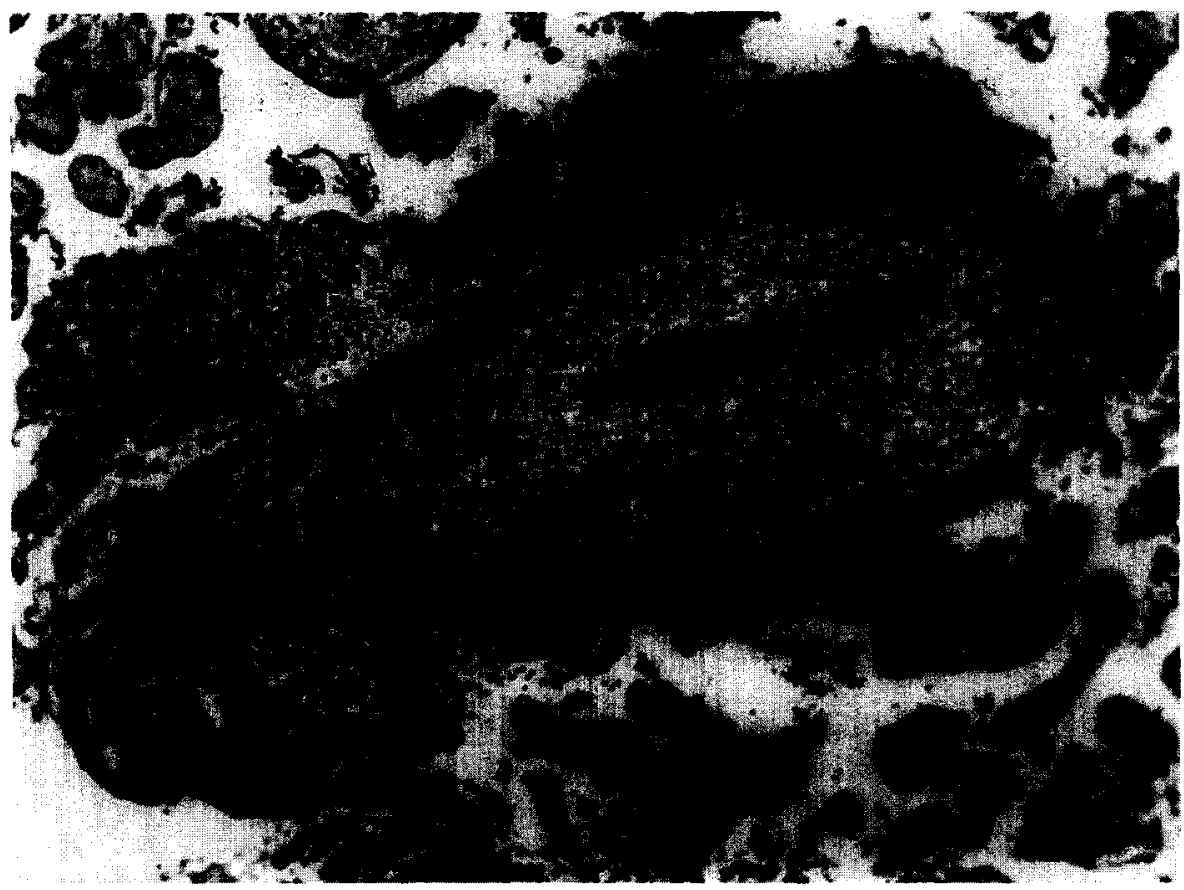

Figure 5. The villous stroma is infiltrated by histiocytes and monocytes around an obliterated vessel and invading the intravillous space $(\mathrm{HE} \times 125)$.

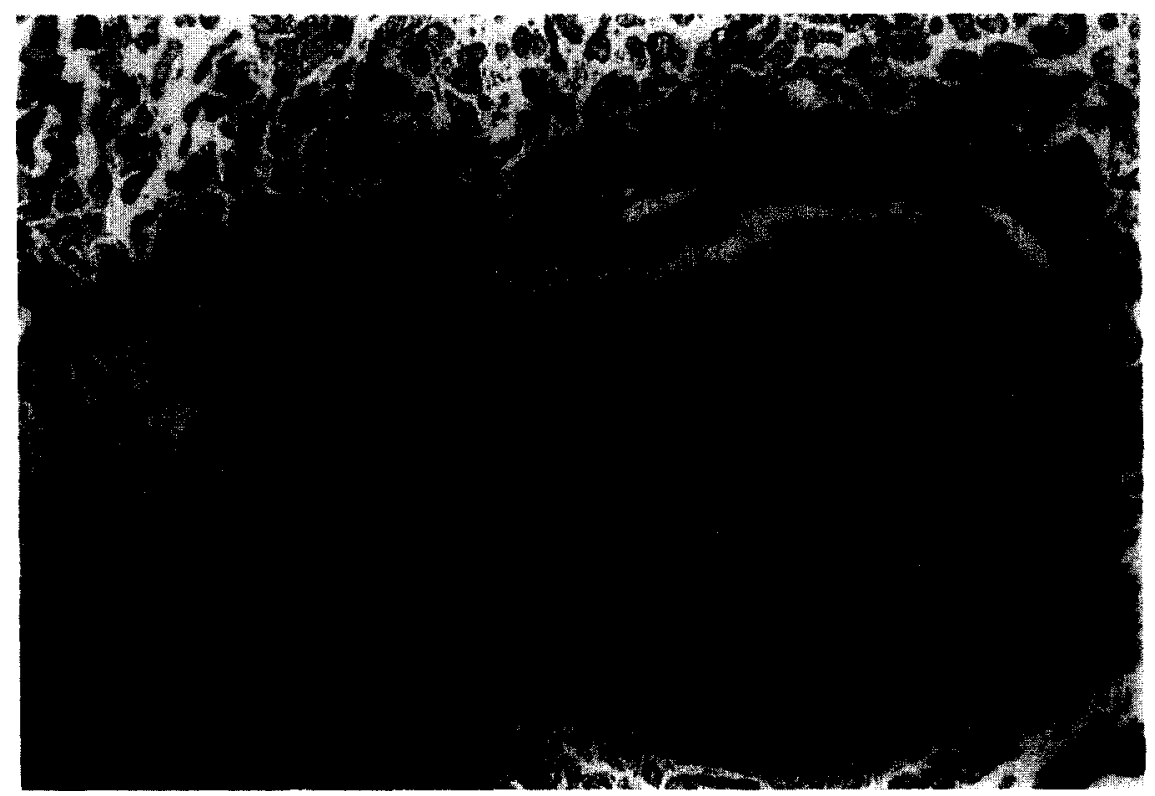

Figure 6. Thrombus involving the decidua and the entire villous plate (Phosphotungstic acid haematoxylin $\times 44$ ). 
Morphological features of the placentae infected by coxsackievirus were almost identical to those observed in the echovirus-infected placentae.

Details of the microscopic placental examination of the control group and the histological findings are shown in Table 4 . In three cases (numbers $5,7,8$ ) there was mild and focal leucocytic infiltration of the chorionic plate and chorium laeve. In three cases (numbers 5, 6, 7) vasculitis was only detected in the chorionic vessels of the placental plate. In one case (number 2) necrotic and proliferative villitis were detected; in case 9, focal disperse reparative villitis was observed. In the intervillous space, maternal leucostasis was present in case 3 . In the decidua, basalis and capsularis clusters of lymphocytes surrounding (or not) the local vessels were always observed; acute infection, necrosis and haemorrhage were not present.

Placental virologic examination. Echovirus types 11, 13, 15, 17, 18, 19, 21, 23, 24 and 25 and coxsackievirus B types 2 and 6 were isolated from 24 per cent of the cases in this series. In this group the women were asymptomatic to enteroviral infection during gestation. The various enteroviruses were isolated from placentae; in four cases they were also isolated from faeces a few days before delivery (numbers $10,11,17,18$ ).

Immunohistology. The results of immunofluorescence and immunoperoxidase assays were similar, demonstrating positivity in the cytoplasm of the cytotrophoblastic cells.

Electron microscopic study. All placentae were observed by electron microscopy. In general, the ultrastructural alterations were similar: hydropic swelling of the cisternae of rough endoplasmic reticulum; deposits of dense granular bodies; presence of polyribosome clusters, some attached to bodies; presence of polyribosome clusters, some attached to dilated elements of rough endoplasmic membrane; intense vacuolization; presence of dense granules inside membrane-bound vesicles and disarrangement of the cytoskeleton (Figure 7). The Golgi apparatus has disappeared as a recognizable entity. At the nuclear level some ultrastructural alterations were seen, including dilatation of the nuclear membrane and condensation of the chromatin. The dilated perinuclear cisterna was continuous at several points with peripheral channels of RER, showing a clean connection among them. Scarce viral particles were found in only four cases. The viruses were localized in the proximity of RER and at the apical top of the cell membrane, some in close association to elements of the cytoskeleton. These alterations were observed in syncytiotrophoblastic cells, some showing intense cytopathogenic effect.

\section{DISCUSSION}

This study outlines an approach to investigating the possible effect of enteroviruses on placental tissues. The properties of enteroviruses justify their consideration as a possible cause of placental and fetal damage as they are highly prevalent and are often associated with viremia. The peculiarities of this group of virus lead us to consider that maternal illness may be associated with a greater risk of transplacental transmission to the fetus late in gestation (Modlin et al, 1981).

As Benirschke \& Driscoll (1967) suggested, the assumption that the virus gains entry into the fetus without ostensible placental injury should be re-evaluated in the light of increasing evidence to the contrary. The participation of the placenta as active tissue in these infections is suggested by limited histological data. As more attempts are made more human viruses are found to be expressed by morphological changes in the placenta, and it seems probable that 


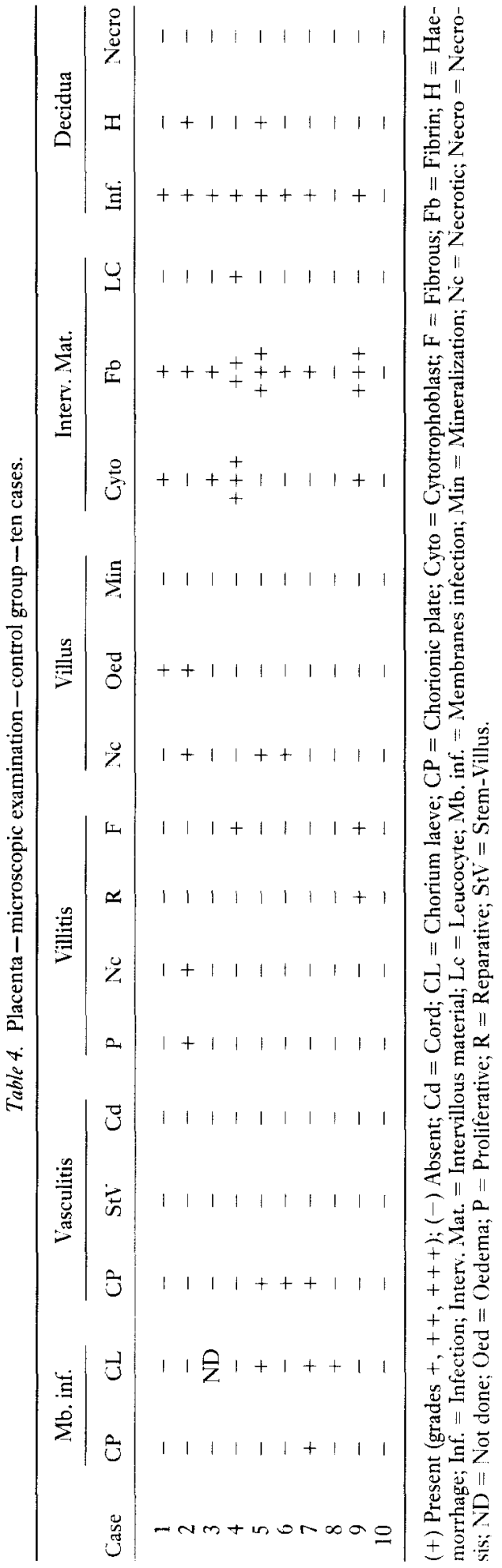



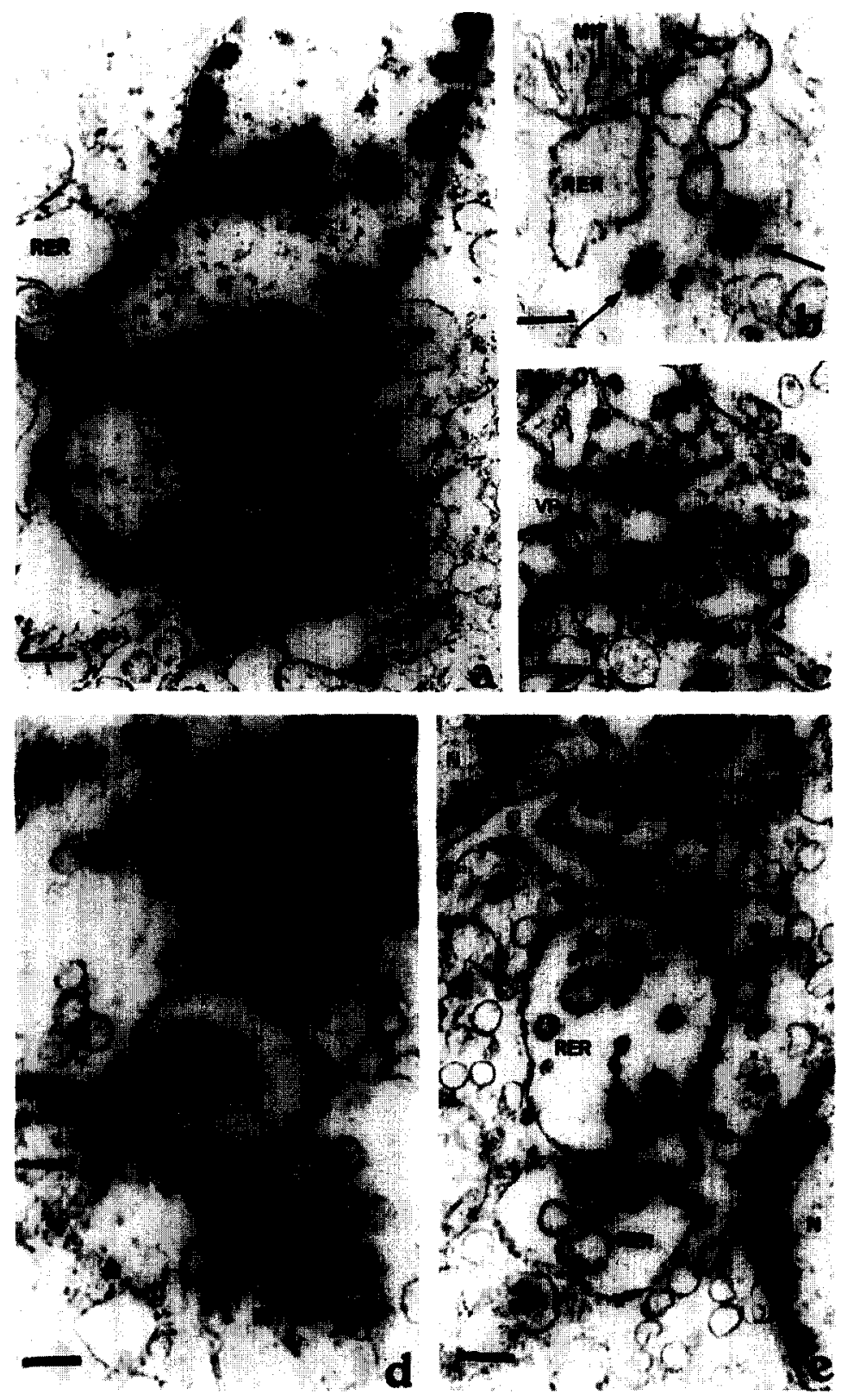

Figure 7. (a) Overview of cytotrophoblast infected with echovirus. Note lysis of cytoplasm, dilated rough endoplasmatic reticulum and dilated perinuclear cistern, continuous at several points with peripheral channels of the RER. Bar $=395 \mathrm{~nm}$. (b) Part of cytotrophoblast infected with echovirus showing dilated elements of RER and mitochondria (MIT); presence of dense granular bodies (arrows). Bar $=160 \mathrm{~nm}$. (c) Part of cytotrophoblast infected with echovirus showing free particles $(39 \mathrm{~nm}$ diameter) nearest to the border membrane. Bar $=195 \mathrm{~nm}$. (d) Dilated RER and mitochondria and Golgi vesicles in part of trophoblastic cells infected with echovirus. Bar $=170 \mathrm{~nm}$. (e) The same as in (d). Bar $=230 \mathrm{~nm}$. 
any micro-organism which can induce human infection can also infect the placenta, and, hence, the fetus.

Rantasallo et al (1960) emphasized that echovirus could be isolated from embryonic tissue and human amniotic cells, but only limited up-to-date information is available concerning transplacental passage of enterovirus. Over the past 25 years several papers have pointed to the possibility of vertical intrauterine enteroviral infection through a placental route (Nogen and Lepow, 1967; Berkovich and Smithwick, 1968; Cherry, Soriano and John, 1968; Hughes et al, 1972; Philip and Larson, 1973; Lake et al, 1976; Modlin, 1980; Jones et al, 1980; Kurnetz et al, 1981; Skeels, Williams and Richer, 1981; Berry and Nagington, 1982; Bose et al, 1983; Modlin, 1988; Rabkin et al, 1988); notwithstanding the fact that morphologic features of placentary tissues are only slightly related or the authors fail to mention placental findings.

In their report of fetal death, Skeels, Williams and Richer (1981) isolated echovirus from the amniotic fluid and the placental examination indicated decreased vascularity and fibrosis of chorionic villi.

We have had the opportunity to study three fetal abortions, whose maternal infection was detected before delivery, by isolation of echovirus types 33 and 27 from faecal specimens and/or placental and fetal tissues. The morphological aspects were similar in all cases, revealing a septic type of placental inflammation, with acute villitis and intervillitis (Garcia et al, 1990).

In the present series, placental lesions compatible with viral infection were observed. The results of macroscopic examination can be considered expressive, as the majority of the specimens demonstrated abnormalities. The placental weight was considered normal in 11 cases and less than normal in eight cases. In some viral infections placental hypoplasia is known (Blanc, 1978; Garcia et al, 1985). Macroscopic features suggesting the presence of placentitis were noted in 17 of 19 specimens. These included mild opalescence of the membranes, abnormal appearance of Wharton's jelly and of umbilical vessels; meconium staining of the membranes of the chorionic plate and umbilical cord. The gross aspect of the maternal surface of some placentae presented features described in the septic type of placental inflammation (Benirschke and Driscoll, 1967) represented by thrombi adherent to the decidua and penetrating the intervillous space, aspect suggestive of vascular pathogenesis.

In two specimens of the control group placentae, meconium staining of the membranes/ umbilical cord had been detected. In two cases, a probable diagnosis of haematogenous placental infection was made (cases 2,10 ). In addition, an ascendent type of amniotic infection was considered in case 8 . The microscopic examination was not expressive in any of them.

Overall, microscopic examination of the 19 placentae revealed mainly vascular lesions in the entire vascular fetal circuit of the organ, from umbilical vessels to the villous capillaries, which suggests that they were caused by a blood-born infection and its morphology is compatible with a viral etiology. It is also worth noting the presence of lesions in the villous plate similar to those found in septicaemic phase of maternal infections, where bacteria were not observed. The distribution of these lesions and the nature of inflammation pointed to an acute type of placental reaction. Similar lesions were observed in other viral placentities such as chickenpox, mumps and in placentae infected by cytomegalovirus in the third trimester of gestation (Garcia, 1963; Garcia et al, 1980; Garcia et al, 1989). It seems that the enteroviruses have a more potent action, as necrosis of placental structures allied to acute intervillitis involved extensive areas of the organ. Allied to the necrotic villous and decidual 
tissues, there were focal areas of detachment of the placenta. In the control group, vasculitis and villitis were rarely observed, as well as areas of acute villous and decidual lesions.

Modlin (1980), in a review of the literature on enterovirus congenital infection, found that of 22 mothers five who gave birth to infants who developed fatal perinatal echovirus infection had had a similar illness late in pregnancy and three had had an emergency caesarean section performed with the diagnosis of premature detachment of placenta.

Some hypotheses encompass all of the available data: (1) maternal enterovirus lead to viremia and virus shedding in the faeces, without viral invasion of the placenta, placentary damage being an unspecific consequence of infection; (2) direct virus-induced injury is not the only possible cause for the described lesions; (3) placental enteroviral infection occurred with consequent placental pathology, but the virus did not cross the placentae as the newborns did not present symptoms of infection in the first days of life. However, the human enteroviruses produce a broad spectrum of clinical responses, ranging from asymptomatic infection to severe, often fatal, multisystem disease (Lake et al, 1976; Modlin, 1986).

Abzug, Rotbart and Levin (1989) examined the transmissibility of enterovirus during late gestation in murines in order to mimic the human parallel of maternal enteroviremia. Despite high titres of virus in the placenta no fetal infection occurred, although intraamniotic inoculation produced a high rate of placental and fetal infection, confirming that fetuses are infectable when the placenta is by-passed. The failure to infect fetuses by maternal parenteral inoculation suggests a protective blockade by the placenta. These authors have also demonstrated that most enterovirus is limited to the decidual plate with little virus detected in the labyrinth, part of the murine organ, which contributes to the fetal blood supply. The restriction of virus from this layer probably prevented viremia from reaching the fetus. These data provide additional evidence supporting the concept of placental defence against enteroviral vertical transmission.

\section{Electron microscopic study}

The cytopathic events observed by electron microscopy resembled those described for the Picornavirus group by Godman, Dalton and Haguenau (1979). Condensed chromatin and intense vacuolization in the host cell may have been a consequence of the reduction of nucleic acid and protein synthesis due to viral replication. Increased permeability and incompetence of the endomembranes occurred as is shown by the hydropic swelling of cisternae of rough endoplasmic reticulum, mitochondria and the presence of new smoothwalled vacuoles. The aggregates seen in the cytoplasm were probably composed of viral RNA and proteins (precusor viral materials) appearing at some stage before their assembly into viral particles. During cytopathic events, the virus is released to the exterior after cell burst. Few mature virus particles were seen in the border of the cell membrane. Mostly, the alterations detected were due to cell lysis and accumulation of viral precursor proteins.

In five of the 19 cases, there was correspondence of positivity for maternal seroconversion and the isolated placental viruses, besides the fact that the same viruses had been isolated from maternal faecal material, at least 10 days before delivery. The high incidence of viral isolation from term placentae could be assumed to be due to faecal placental contamination.

\section{ACKNOWLEDGEMENTS}

We would like to thank Mrs Carolina Bernadete Saraiva do Nascimento, Mr Marcelo Porciuncula de Souza and Mr Carlos Bacelar for their expert assistence in the preparation of the manuscript. 


\section{REFERENCES}

Abzug, M. A., Rotbart, H. A. \& Levin, M.J. (1989) Demonstration of a barrier to transplacental passage of murine enteroviruses in late gestation. Fournal of Infectious Diseases, 159, 761-765.

Amstey, M. S., Miller, R. K., Menegus, M. A. \& Sant'Agnese, P. A. (1988) Enterovirus in pregnant women and the perfused placenta. American foumal of Obstetrics and Gynecology, 158, 775-782.

Baskin, J. L., Soule, E. H. \& Mills, S. D. (1950) Polyomielitis of the newborn. Pathologic changes in two cases. American Zoumal of Diseases of Children, 80, 10-21.

Basso, N. G. S., Fonseca, M. E. F., Garcia, A. G. P., Zuardi, J. A. T., Silva, M. R. \& Outanni, H. N. (1990) Enterovirus isolation from foetal and placental tissues. Acta Virologica, 34, 31-34.

Benirschke, K. \& Driscoll, S. G. (1967) The Pathology of the Human Placenta. Berlin: Springer-Verlag. 512 pp.

Berkovich, S. \& Smithwick, E. M. (1968) Transplacental infection due to echovirus type 22. Foumal of Pediatrics, $72,94-96$.

Berry, P. J. \& Nagington, J. (1982) Fatal infection with echovirus 11. Archives of Diseases of Children, 57, 22-29.

Blanc, W. A. (1978) Pathology of the placenta and cord in some viral infections. In Viral Disease of the Fetus and Nemborn (Ed.) Hanshaw, J. B. \& Dudgeon, J. H., Volume 17, pp. 237-258. Philadelphia: W. B. Saunders.

Bose, C. L., Gooch, M., Sanders, G. D. \& Bucciarelli, R. L. (1983) Dissimilar manifestations of intrauterine infection with echovirus 11 in premature twins. Archives of Pathology ES Laboratory Medicine, 107, 361-363.

Cherry, J. D., Soriano, F. \& John, C. L. (1968) Search for perinatal viral infection: a prospective clinical, virological and serological study. American foumal of Diseases of Children, 116, 245-250.

Dalton, A. J. \& Haguenau, F. (1979) Ultrastructure of Animal Viruses and Bacteriophages, Volume 5, pp. 133153. New York: Academic Press.

Garcia, A. G. P. (1963) Fetal infection in chickenpox and alastrim with histopathological study of the placenta. Pediatrics, 32, 895-901.

Garcia, A. G. P., Pereira, J. M. S., Vidigal, N., Lobato, Y. Y., Pegado, C. S. \& Branco, J. P. C. (1980) Intrauterine infection with mumps virus. Obstetrics \& Gynecology, 56, 756-759.

Garcia, A. G. P., Marques, R. L. S., Lobato, Y. Y., Fonseca, M. E. F. \& Wigg, M. D. (1985) Placental pathology in congenital rubella. Placenta, 6, 281-295.

Garcia, A. G. P., Fonseca, M. E. F., Marques, R. L. S. \& Lobato, Y. Y. (1989) Placental morphology in cytomegalovirus infection. Placenta, 10, 1-19.

Garcia, A. G. P., Basso, N. G. S., Fonseca, M. E. F. \& Outanni, H. N. (1990) Congenital echovirus infection Morphological and virological study of fetal and placental tissue. Fournal of Pathology, 160, 123-127.

Hughes, J. R., Wilfert, C. M., Moore, M., Benirschke, K. \& Hoyos-Guevara, E. (1972) Echovirus 14 infection associated with fatal neonatal hepatic necrosis. American fournal of Diseases of Children 123, 61-67.

Jones, M. J., Kolb, M., Votava, H. J., Johnson, R. L. \& Smith, T. F. (1980) Intrauterine echovirus type 11 infection. Mayo Clinic Proceedings, 55, 509-512.

Kibrick, S. \& Benirschke, K. (1958) Severe generalized disease (encephalomyocarditis) occurring in the newborn period and due to infection with coxsackievirus group B. Pediatrics, 22, 857-875.

Kurnetz, R., Cacciarelli, A., Egere, R. \& Yang, S. S. (1981) Neonatal infection. Fournal of Pediatrics, 99, 822-826.

Lake, A. M., Laver, B. H., Clark, J. C. \& McIntosh, K. (1976) Enterovirus infections in neonates. Fournal of Pediatrics, 89, 787-791.

Melnick, J. L., Wenner, H. A. \& Philips, C. A. (1979) Enteroviruses. In Viral, Richettsial and Chlamydial Infections. (Ed.) Lennette, E. H. \& Schmidt, N. J. pp. 471-534. Washington: American Public Health Association.

Modlin, J. F. (1980) Fatal echovirus 11 disease in premature neonates. Pediatrics, 66, 775-780.

Modlin, J. F., Polk, B. F., Horton, P., Etkind, P., Crane, E. \& Spiliotes, A. (1981) Perinatal echovirus infection: risk of transmission during a community outbreak. New England 7ourmal of Medicine, 305, 368-371.

Modlin, J. F. (1986) Perinatal echovirus infection: Insights from a literature review of 61 cases of serious infection and 18 outbreaks in nurseries. Review of Infectious Diseases, 8, 918-926.

Modlin, J. F. (1988) Echovirus infections of newborn infants. Pediatric Infectious Diseases, 7, 311-312.

Morisset, R., Kurstak, C. \& Kurstak, E. (1974) Diagnosis of Herpes simplex infections with immunoperoxidase. In Viral Immunodiagnosis. (Ed.) Kurstak, E. \& Morisset, R. pp. 31-39. New York: Academic Press.

Nahmias, A. J., Shore, S. L. \& Del Buono, I. (1974) Diagnosis by immunofluorescence of human viral infections with emphasis on herpes simplex viruses. In Viral Immunodiagnosis. (Ed.) Kurstak, E. \& Morisset, R., pp. 157-171. New York: Academic Press.

Nogen, A. \& Lepow, M. (1967) Enteroviral meningitis in very young infants. Pediatrics, 40, 617-626.

Philip, A. G. S. \& Larson, E. J. (1973) Overwhelming neonatal infection with echo 19 virus. Fournal of Pediatriss, 82, 391-397.

Philippe, E. (1974) Histopathologie Placentaire. Paris: Masson et Cie. 168 pp.

Rabkin, C. S., Telzak, E. E., Ho, M. H., Goldstein, J. \& Bolton, W. (1988) Outbreak of echovirus 11 infection in hospitalized neonates. Pediatric Infectious Diseases, 7, 186-190.

Rantasallo, I., Pentinen, K., Saxen, L. \& Ojala, A. (1960) Echo 9 virus antibody status after an epidemic period and the possible teratogenic effect of the infection. Annales Paediatriae Fenniae, 6, 175-184.

Skeels, M. R., Williams, J. \& Richer, F. M. (1981) Perinatal echovirus infection (letter). New England foumal of Medicine, 305, 1529.

Toce, S. S. \& Keenan, W. J. (1988) Congenital echovirus 11 pneumonia in association with pulmonar hypertension. Pediatric Infectious Diseases, 7, 360-362. 